\title{
Exploring karst landscapes: new prehistoric sites in south-central Ethiopia
}

\author{
Yonatan Sahle ${ }^{1, *}$, Domenico Giusti ${ }^{2}$, Tegenu Gossa ${ }^{3} \&$ Hila Ashkenazy $^{1}$
}

Archaeological reconnaissance and test excavation conducted in south-central Ethiopia reveal the region's rich Stone Age and Holocene archaeology. Ongoing lithic, faunal and dating analyses aim to understand chronological and behavioural contexts of prioritised rockshelters as part of a newly launched project. Speleothems in some of the caves promise high-resolution palaeoclimatic reconstruction.

Keywords: Ethiopia, Holocene, Stone Age, speleothems, caves, palaeoclimate

\section{Introduction}

Outside of the Rift Valley, the lowlands of Ethiopia have received little archaeological research attention, with the semi-arid lowlands in the south-central parts of the country remaining particularly underexplored. The dearth of archaeological data from securely dated and fairly continuous sequences limits a comprehensive understanding of the later prehistory of the Horn of Africa (e.g. Clark 1954; Brandt 1986; Assefa et al. 2014; Lesur et al. 2014). The persistence of poorly defined, traditional higher-level classifications, such as the Later Stone Age, add further complications by masking technological and behavioural variability across the Terminal Pleistocene and Holocene. Long-term research programmes aimed at resolving these issues are long overdue in this region. We report here the discovery of several cave and rockshelter sites from previously unexplored limestone karst formations along the Arsi-Bale lowlands of Ethiopia.

\section{Survey and test excavation}

In 2017, our team conducted a survey of the karst landscapes across the semi-arid Arsi-Bale lowlands and margins (Figure 1). This led to the discovery of 27 caves and rockshelters in 12 loci spanning various geological, topographic and ecological zones. Karst landscapes in two localities were identified as particularly promising for further investigations by virtue of their material remains, rock paintings and, in some locations, speleothems (mineral deposits) suitable for high-resolution palaeoclimatic reconstruction.

The first group of caves are aligned along a prominent, north-facing karst ledge overlooking the Loko River in the Gololcha district. Positioned at an elevation of $1230 \mathrm{~m}$, one of the Loko caves is $40 \mathrm{~m}$ wide, $15 \mathrm{~m}$ deep and $20 \mathrm{~m}$ high (Figure 2a). Speleothems in this cave occur

1 DFG Center for Advanced Studies, University of Tübingen, Rümelinstrasse 23, 72070 Tübingen, Germany

2 Senckenberg Centre for Human Evolution and Palaeoenvironment (HEP) \& University of Tübingen, Rümelinstrasse 23, 72070 Tübingen, Germany

3 Institute of Archaeology, The Hebrew University of Jerusalem, Mount Scopus, 91905 Jerusalem, Israel

* Author for correspondence (Email: yonatan.sable@ifu.uni-tuebingen.de)

(C) Antiquity Publications Ltd, 2019

ANTIQUITY 93 370, e21 (2019): 1-6

https://doi.org/10.15184/aqy.2019.94 


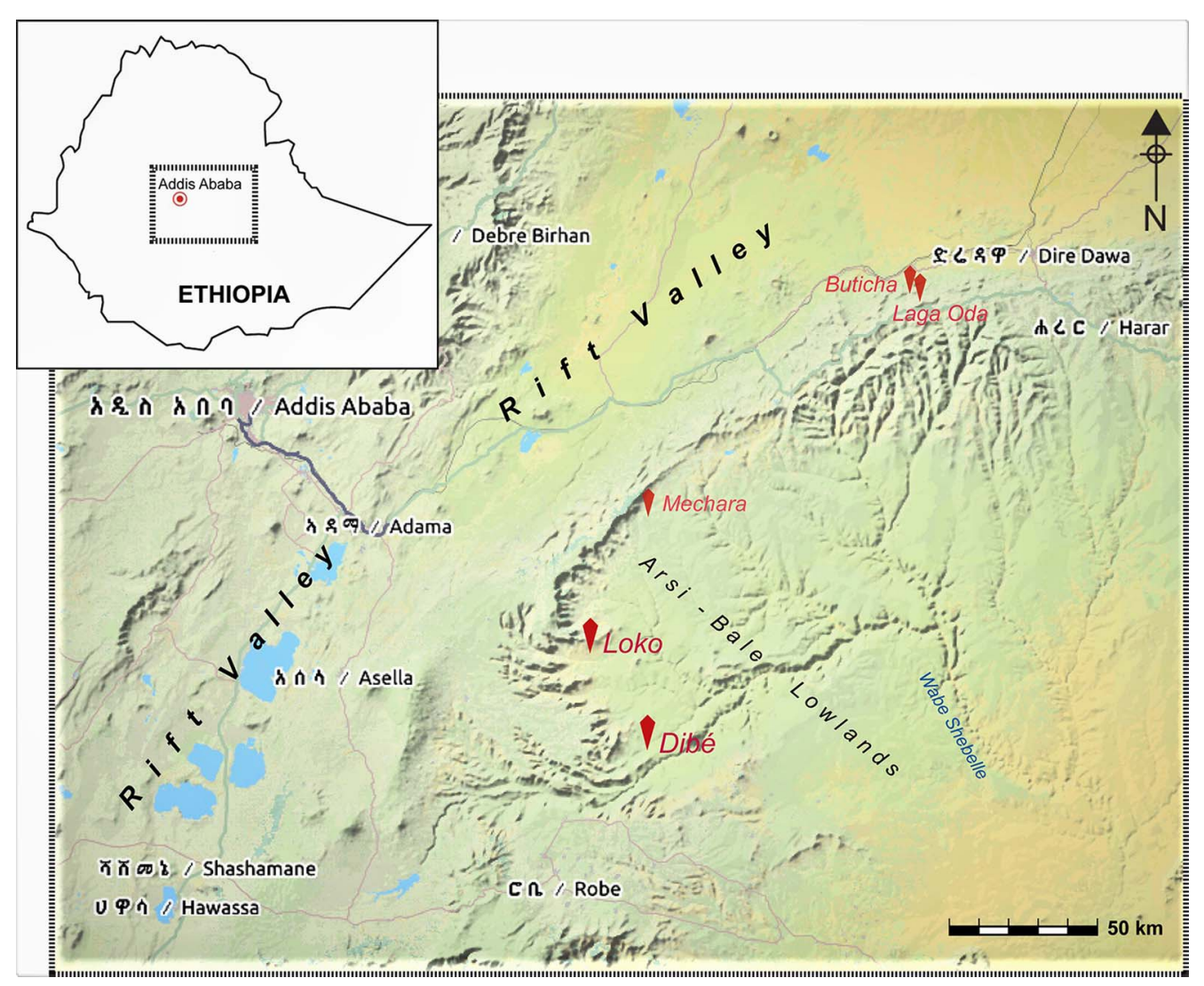

Figure 1. Map showing the location of limestone karst systems and archaeological sites in south-central and eastern Ethiopia (map credit: OpenStreetMap).

as both stalagmites and stalactites that are up to $4.5 \mathrm{~m}$ high, and $50 \mathrm{~mm}$ in diameter. Lithic artefacts are made from diverse raw materials and include flaked river cobbles, laminar flakes and blades, Levallois products, and multidirectional cores. An ellipsoidal cobble recovered partially exposed on the floor (Figure 2c) probably represents a grindstone, although a conclusive statement requires microscopic analysis. Several pieces of charcoal and coprolite were also documented and sampled. In most of the Loko caves, the silty to clayey aeolian sediments show limited signs of post-depositional disturbance, and no bioturbation inside of the dripline (a line on the ground at the cave entrance formed by drips from the rock above), thus proving to be suitable for future systematic excavation.

The second significant cluster of archaeological sites occurs in the karst landscape marking the lowlands of the Seru district. Here, rockshelters are located along the walls of steep river gorges or on scarps overlooking wadis. The broader Seru lowlands, marked off from the adjacent plateaus by an abrupt elevation drop of $>1000 \mathrm{~m}$ (Figure 1), contain a regionally extensive Jurassic limestone (Assefa 1988). The karst landscape along the Dibé wadi particularly dominates here.

Prominent limestone ridges on either side of the Dibé gorge offer a commanding view of the wadi floor and the adjoining plain with short-growth plants and shrubs. The gorge (C) Antiquity Publications Ltd, 2019 


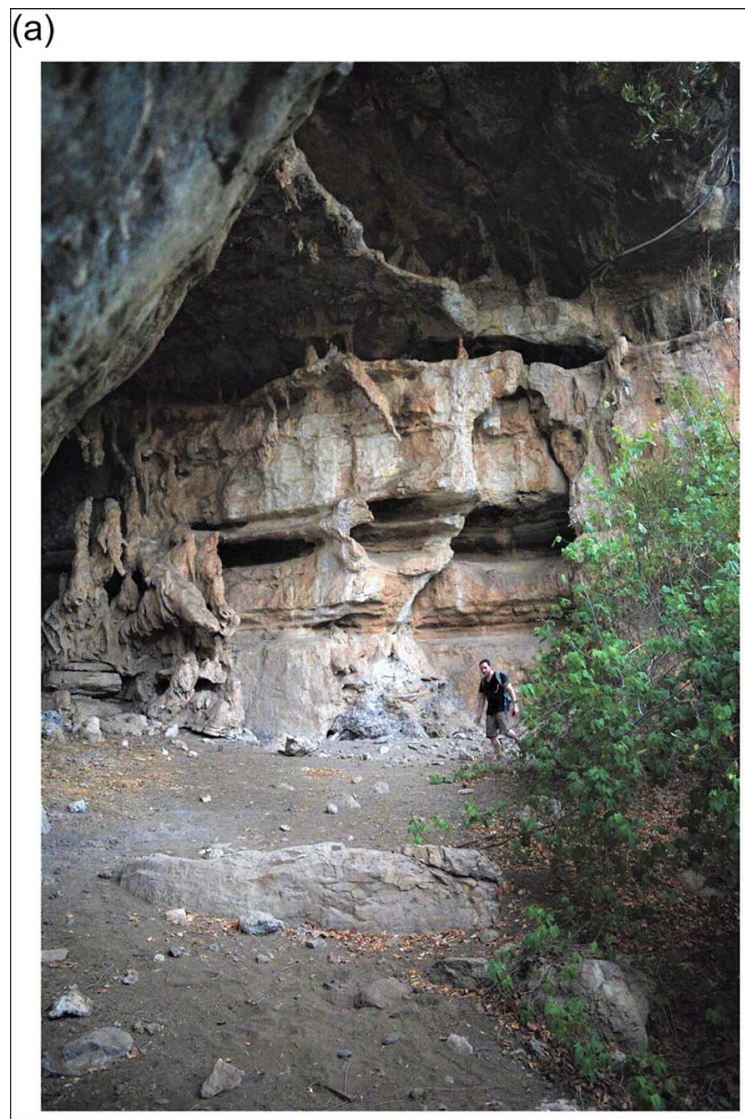

(b)
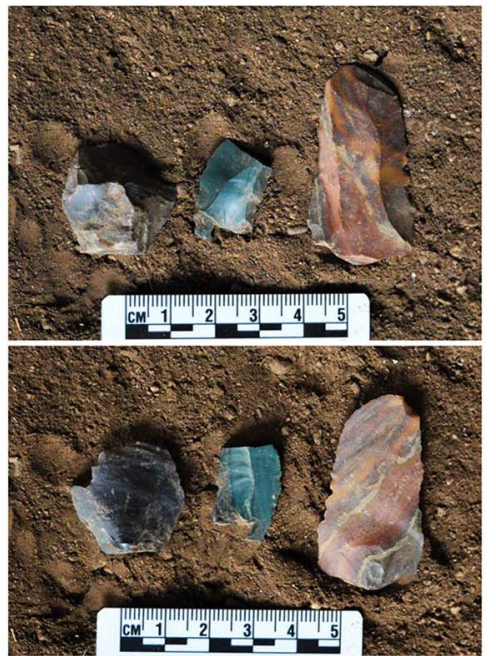

(c)

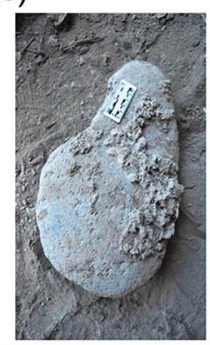

(d)

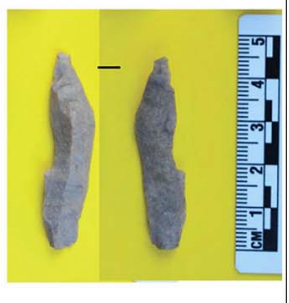

Figure 2. Loko: a) the largest cave with speleothems and artefacts; $b$ ) Levallois flakes (top = dorsal view; bottom = ventral view); c) 'grindstone'; d) small laminar blade (photographs by Yonatan Sable).

contains several rockshelters with surface-scattered artefacts and rock paintings, conceivably due to its strategic location (Figure $3 \mathrm{a}-\mathrm{c}$ ). The exceptionally rich scatter of lithic artefacts, faunal remains and a panel of rock art on its back wall led to our prioritisation of one of the Dibé rockshelters for closer investigation. In 2018, we conducted controlled surface collection and test excavation of this rockshelter.

The closely studied Dibé rockshelter faces south-west, with the current dripline measuring only a maximum of $4 \mathrm{~m}$ from the back wall, thus preserving a rather small part of the ancient living floor (Figure $3 \mathrm{~b}-\mathrm{c}$ ). The density of eroded artefacts and the proximity of the fronting terrace and shelter talus (an accumulation of debris extending outwards from the dripline) to the wadi added a sense of urgency to the closer examination of this rockshelter. Particularly interesting is a surface scatter of prismatic blades, discoidal cores, a Levallois point, several backed microliths, and pieces exhibiting the micro-burin technique (Figure 3d-f). Adherent carbonate matrix on most of the exposed lithic and faunal pieces not only attested to the recent erosion of these, but also to the excavation potential in a setting devoid of 'Neolithic' finds, such as potsherds. 
(a)

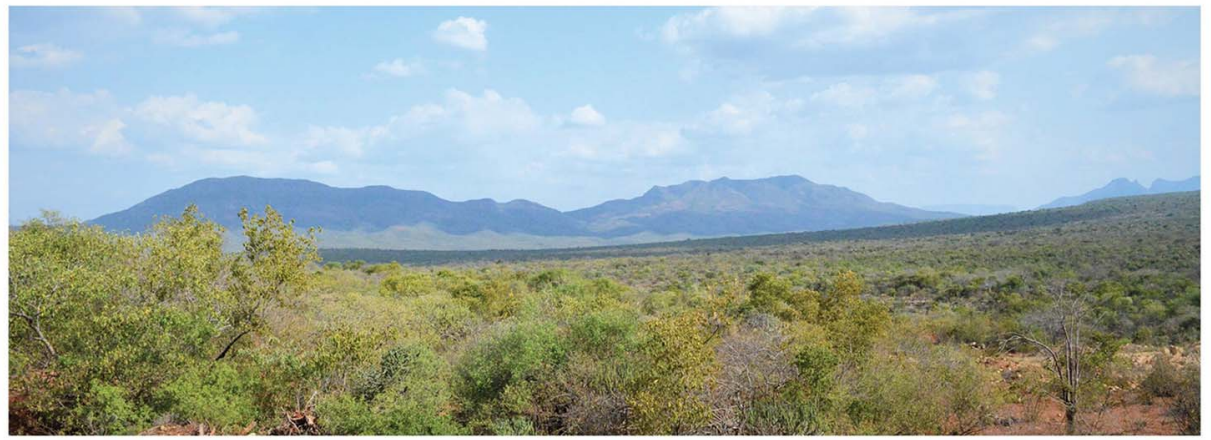

(b)

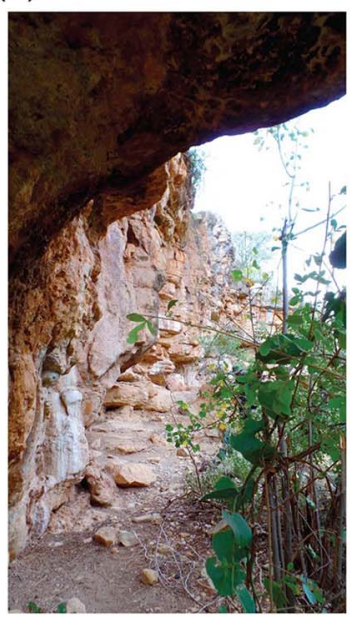

(d)

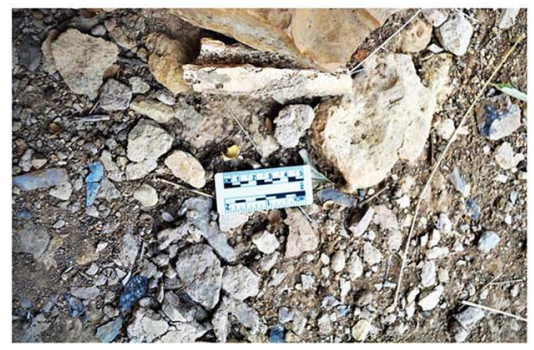

(c)

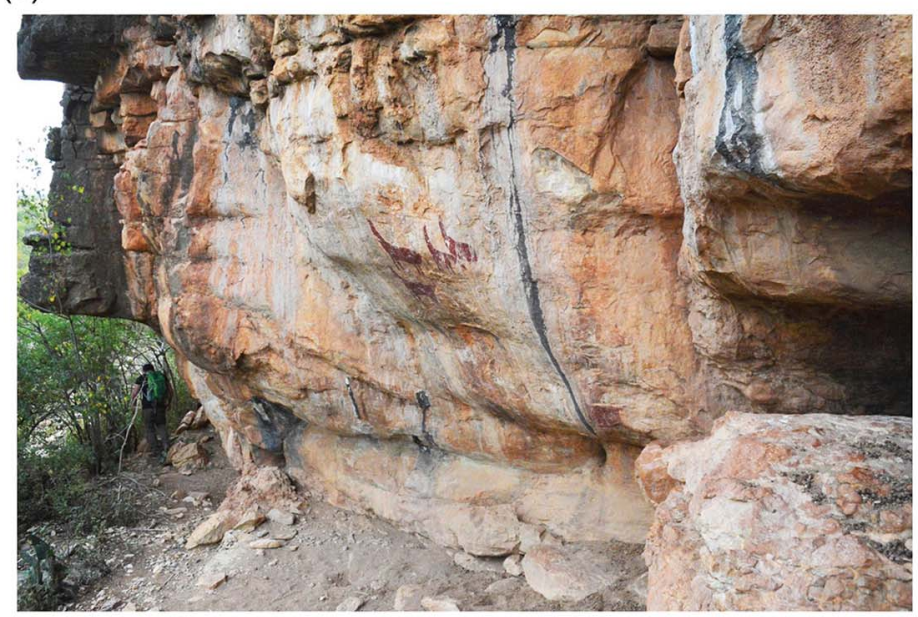

(e)

(f)

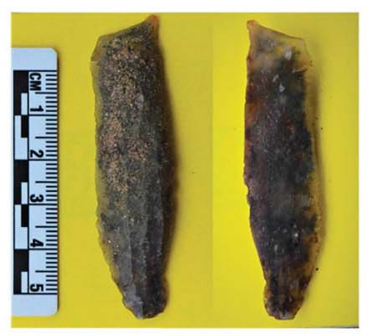

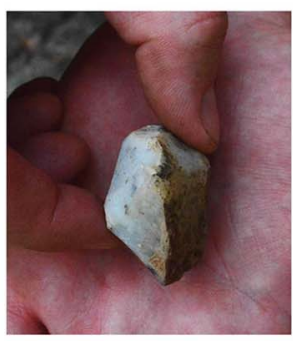

Figure 3. Dibé: a) panoramic view of the Seru lowlands; b) Dibé limestone wall as viewed from the main rockshelter; c) rock art in the main rockshelter (note the dripstone superimposing the paintings); d) surface-scattered artefacts and fossils; e-f) prismatic blade and discoid from the Dibé main rockshelter (photographs by Yonatan Sable).

Finds from a $67 \mathrm{~m}^{2}$ surface were collected from gridded units and bagged separately. Based on artefact density, clinging matrix and suitability for excavation, a $2 \times 1 \mathrm{~m}$ area was test-excavated near the back wall in the northern corner of the shelter. Excavation followed (C) Antiquity Publications Ltd, 2019 
a combination of natural and artificial stratigraphy, so that spits normally followed the natural change in sediment type, with an artificial $0.1 \mathrm{~m}$ break where no such change was noticed. The squares were excavated to a maximum depth of $0.75 \mathrm{~m}$ below datum. The test excavation did not reach bedrock. Ensuing field seasons will expand excavations both laterally and vertically.

A total of 5285 artefacts were collected from the ground's surface, and 1885 were excavated from Dibé. Lithic raw materials are dominated by chert, whereas other raw materials include obsidian, basalt and quartz. Detailed examination of the archaeological materials as well as radiocarbon dating of the sequence are currently underway. All archaeological remains are housed in the National Museum of Ethiopia, Addis Ababa.

\section{Rock art}

The Dibé rock art (Figure 3c) represents yet another unique aspect that has added to the prioritisation of archaeological excavations and chronological work there. Interestingly, the Dibé rock paintings lack the stylised or naturalistic bovine depictions common elsewhere in the country—where horns, humps or udders are often exaggerated (Brandt \& Carder 1987). The earliest rock paintings from Ethiopia are estimated to date to the Mid-Holocene arid phases (which started c. 6000 years BP), based on stylistic and thematic attributes. Our initial stylistic comparisons suggest that anthropomorphic, animal and possibly hunting and/or herding depictions at the Dibé rockshelter show salient features that contrast those known from across the Horn of Africa. Ongoing studies of thematic, chronological and other aspects of the Dibé rockshelter paintings are expected to provide interesting information. If current attempts to date the Dibé figurative art directly using U-series methods on calcite samples superimposing the pigment layer succeed, they will add to a very limited number of securely dated examples on the African continent (Richter \& Vogelsang 2008; Bonneau et al. 2017). Considering the proximity of the surveyed areas to karst systems with detailed palaeoclimatic data (Asrat et al. 2018), the launching of such a long-term archaeological research programme in this region promises a wealth of information.

\section{Acknowledgements}

Research was conducted under permission from the Authority for Research and Conservation of Cultural Heritage of Ethiopia to Y.S. We are grateful for kind support from D. Dagne, S. Scheiffele, K. Geleta and several other colleagues in the Arsi Zone. Funding support for the 2018 fieldwork at Dibé was generously provided to Y.S. by the Paleontological Scientific Trust.

\section{References}

Asrat, A., A. Baker, M.J. Leng, J. Hellstrom, G. Mariethoz, I. Boomer, D. Yu, C.N. Jex \& J. GunN. 2018. Paleoclimate change in Ethiopia around the last interglacial derived from annually resolved stalagmite evidence. Quaternary Science Reviews 202: 197-210.

https://doi.org/10.1016/j.quascirev.2018.06.016
Assefa, G. 1988. Potential hydrocarbon-generating rock units within the Phanerozoic sequence of the Ogaden Basin, Ethiopia: a preliminary assessment using the Lopatin model. Journal of Petroleum Geology 11: 461-72. https://doi.org/10.1111/j.1747-5457.1988. tb00832.x

Assefa, Z., D. Pleurdeau, F. Duquesnoy, E. Hovers, O. Pearson, A. Asrat \& Y.M. Lam. 
2014. Survey and explorations of caves in southeastern Ethiopia: Middle Stone Age and Later Stone Age archaeology and Holocene rock art. Quaternary International 343: 136-47. https://doi.org/10.1016/j.quaint.2013.07.132

Bonneau, A., D. Pearce, P. Mitchell, R. Staff, C. Arthur, L. Mallen, F. Brock \& T. Higham. 2017. The earliest directly dated rock paintings from southern Africa: new AMS radiocarbon dates. Antiquity 91: 322-33. https://doi.org/10.15184/aqy.2016.271

Brandt, S.A. 1986. The Upper Pleistocene and Early Holocene prehistory of the Horn of Africa. African Archaeological Review 4: 41-82.

Brandt, S.A. \& N. Carder. 1987. Pastoral rock art in the Horn of Africa: making sense of udder chaos. World Archaeology 19: 194-213. https://doi.org/10.1007/BF01117035

Clark, J.D. 1954. The prehistoric cultures of the Horn of Africa. Cambridge: Cambridge University Press.

Lesur, J., E.A. Hildebrand, G. Abawa \& X. Gutherz. 2014. The advent of herding in the Horn of Africa: new data from Ethiopia, Djibouti and Somaliland. Quaternary International 343: 148-58. https://doi.org/10.1016/j.quaint.2013.11.024

Richter, J. \& R. Vogelsang. 2008. Rock art in north-western central Namibia-its age and cultural background, in C. Limpricht \& M. Biesele (ed.) Heritage and cultures in modern Namibia-in-depth views of the country: 37-46. Göttingen: Klaus Hess.

Received: 2 May 2019; Revised: 23 May 2019; Accepted: 29 May 2019

(C) Antiquity Publications Ltd, 2019 